\title{
Evaluation of Integrated Energy System in Airports Based on Comprehensive Weighting Method
}

\author{
Ji Jiayin ${ }^{1}$, Chen $\mathrm{Kang}^{2,3, *}$ \\ ${ }^{1}$ Xi'an University of Architecture and Technology, 710055 Xi'an, Shaanxi, China \\ ${ }^{2}$ Northwest Engineering Corporation Limited, 710065 Xi'an, Shaanxi, China \\ ${ }^{3}$ Xi'an Jiaotong University, State Key Laboratory of Multiphase Flow in Power Engineering, 710049 Xi'an, Shaanxi, China
}

\begin{abstract}
Airport is a typical integrated energy system in a park with various energy requirements. In this paper, a multi-dimensional quantitative analysis of system performance indicators was conducted by using a comprehensive weighting method based on the analytic hierarchy process (AHP) and anti-entropy weight method. A distributed energy system evaluation matrix model was used to evaluate and compare different integrated energy designs. The results showed that electric boilers would increase the primary energy ratio and primary energy consumption than the ones caused by gas boilers. Also, energy storage devices could significantly decrease pollutant emissions of integrated energy systems but would increase investment costs and reduce the economic indicators of system solutions. In a word, the configuration with ice storage, combined cooling, heating and power (CCHP), gas boiler, ground source heat pump (GSHP), air source heat pump (ASHP), and absorption chiller had the best evaluation indicators.
\end{abstract}

\section{Introduction}

With the development of the Energy Internet, integrated energy systems will become more complex and intelligent with the in-depth integration of equipment, energy, and internet information. It not only involves various energy subsystems of power, heating, cooling, and gas, and multiple energy conversion systems but also is closely related to economic, environmental, reliability, meteorological parameters, energy resources, and topographic environment. The urgency of energy reform, the geographical location of the energy system, the contribution of society, and the energy policy of the government play a decisive role in determining if technological innovation and management improvement of an integrated energy system are necessary.

Integrated energy systems break the existing pattern that planning, design, and operation of various energy supply systems such as power, gas, heating, and cooling systems are separated. In the planning, design, construction, and operation stages of the integrated energy systems, a new regional energy supply system that makes full use of renewable energy is formed through the coordination and optimization of various sectors, including the production, transmission, distribution, conversion, storage, and consumption of various types of energy [1-2]. The integrated energy system includes different types of energy such as electricity, heat, gas, and cold. The conversion and transmission characteristics of each type of energy are different. For example, electricity can be easily transmitted and converted while heat and cold can be easily stored. In multi-energy networks, that energy sources can be coupled and complementary is of great importance. The construction of an integrated energy system can promote the consumption of renewable energy and improve the efficiency of energy use, so reasonable multi-energy planning is especially important. Shao et al. [3] analyzed and studied multi-energy planning. Based on each subsystem and with the power system as the core, the characteristics of each subsystem were obtained so that the energy sources could be utilized in a complementary manner. Considering the operational safety constraints of power grids and natural gas networks, a multi-stage joint planning model with gas network and power grid coupled was proposed in the literature [15] with the aim of minimizing the investment cost and operation cost.

Meanwhile, a comprehensive evaluation of the new regional energy supply system using multiple types of energy is required to ensure the reliability, economic efficiency, and cleanliness of the operation of the new system. Hong et al. [4] established an evaluation index system for smart parks from various dimensions such as social, environmental, engineering, economic, and energy. Wu et al. [5-9] used different weighting methods, such as the projection pursuit method, to assign weights to the indicators of different systems. At present, the research of energy systems mainly focuses on design optimization [10-14], and few studies were conducted on the postproject evaluation of regional integrated energy systems. Peng et al. [15] constructed a distributed energy system evaluation system based on the IAHP-coefficient of variance method, which could be used for the evaluation of the design solution of regional integrated energy systems.

* Corresponding author: chen_kang@xjtu.edu.cn 
Currently, there are many studies related to the Energy Internet, smart power grid, integrated energy system, and system evaluation, but no system has been formed yet to meet the needs of the industry. Therefore, it is necessary to establish a comprehensive evaluation model through an evaluation index system and corresponding quantitative evaluation method for comprehensive multi-energy utilization so as to make a comprehensive evaluation of the energy system.

\section{Comprehensive Energy System Evaluation Model for Airports}

\subsection{Integrated Energy System Physical Model for Airports}

An "energy station + energy island" integrated solution was adopted. A comprehensive energy station was set up, and CCHP, ice storage, and gas boiler were used. Several energy islands were installed in the terminal, and ASHP was used. The main role of the ASHP system is to regulate peaks and provide medium-temperature chilled water $\left(12^{\circ} \mathrm{C}\right)$ by taking advantage of the low valley electricity prices when the local cooling demand is required at night.

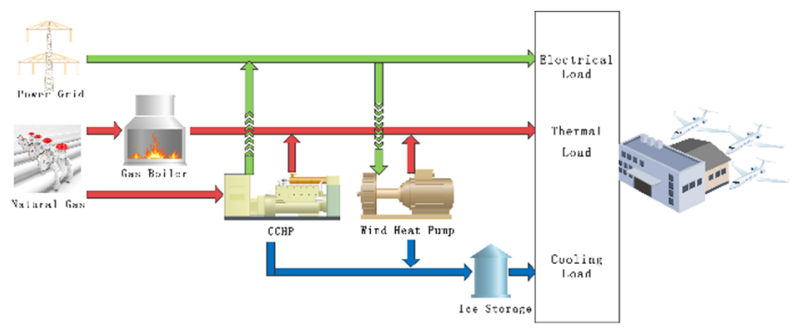

Fig. 1. Integrated Energy System of Airports

\subsection{Airport Load Conditions}

Take an airport as an example, its electric load is 117,500 $\mathrm{kVA}$, and its heat and cold loads are shown in Table 1.

Table 1. Heat and cold loads

\begin{tabular}{|c|c|c|c|c|c|c|}
\hline \multicolumn{2}{|c|}{ Name } & $\begin{array}{c}\text { Floor } \\
\text { Area } \\
/ \mathrm{km}^{2}\end{array}$ & $\begin{array}{c}\text { Cold } \\
\text { Indicat } \\
\text { or } \\
/ \mathrm{W} \cdot \mathrm{m}^{-2}\end{array}$ & $\begin{array}{c}\text { Cold } \\
\text { Load/ } \\
\mathrm{MW}\end{array}$ & $\begin{array}{c}\text { Heat } \\
\text { Indicat } \\
\text { or } \\
/ \mathrm{W} \cdot \mathrm{m}^{-2}\end{array}$ & $\begin{array}{c}\text { Heat } \\
\text { Loa } \\
\mathrm{d} / \mathrm{M} \\
\mathrm{W}\end{array}$ \\
\hline \multirow{3}{*}{-nal } & $\begin{array}{c}\text { Terminal } \\
\text { Building }\end{array}$ & 0.6 & 160 & 96 & 120 & 72 \\
\cline { 2 - 7 } & $\begin{array}{c}\text { Reserved } \\
\text { Land }\end{array}$ & 0.2 & 160 & 32 & 120 & 24 \\
\hline \multirow{5}{*}{ GTC } & $\begin{array}{c}\text { Ground } \\
\text { Transpor- } \\
\text { tation } \\
\text { Centre }\end{array}$ & 0.1 & 160 & 16 & 120 & 12 \\
\cline { 2 - 7 } & $\begin{array}{c}\text { Parking } \\
\text { Building }\end{array}$ & 0.23 & 90 & 20.7 & 100 & 23 \\
\hline
\end{tabular}

The operating hours of the airport are generally all day long, that is, from 0:00 to 23:00. The load between different time periods varies greatly, and the loads of a typical winter day and a typical summer day are shown in Figures 2 and Figure 3. A typical winter day has a more pronounced load segmentation in terms of the heat load, and the heat load is mainly divided into two categories, that is, the heating load and the hot water supply load. The heat load changes significantly with time. The electric load does not vary much throughout the day, which shows a flat trend. Also, a typical summer day has a more pronounced load segmentation in terms of the cold load. Since the cold load is mainly provided by the electric refrigerator or double duty chiller units, the electric load and the cold load change in the same way.

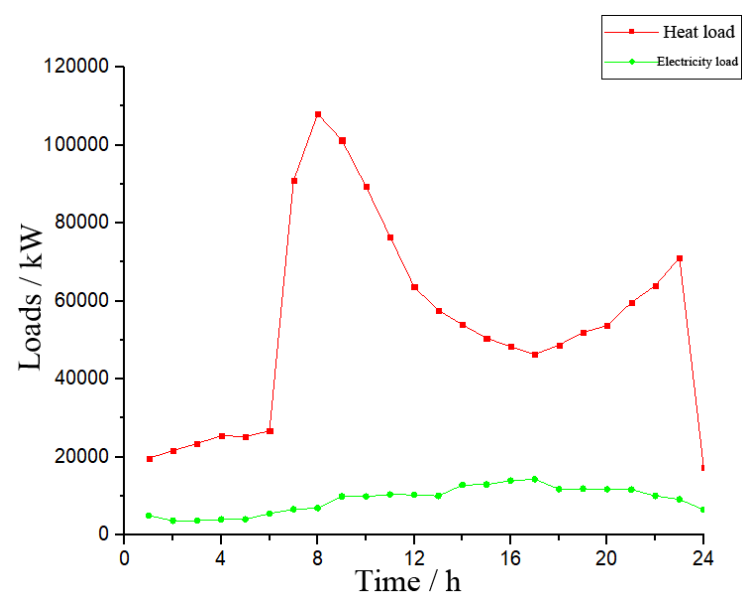

Fig. 2. Heat Load and Cold Load of a Typical Winter Day

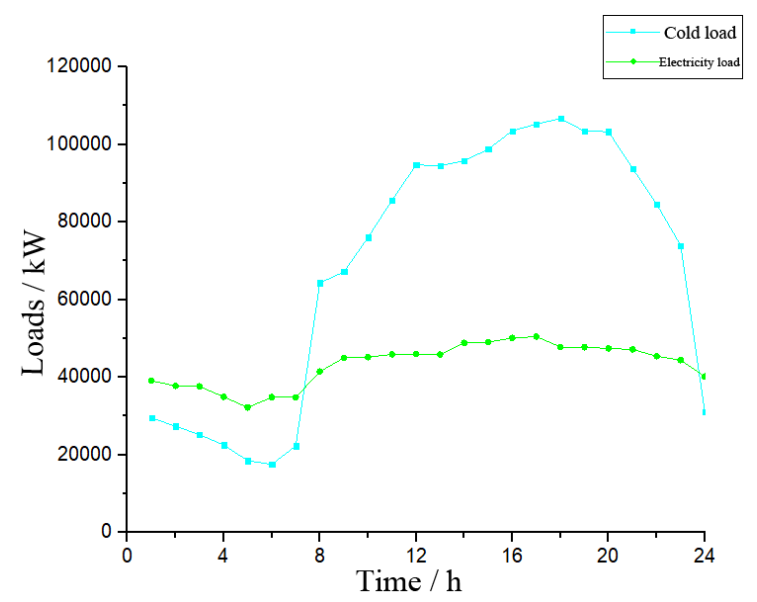

Fig. 3. Heat Load and Cold Load of a Typical Summer Day

\subsection{Captions/numbering}

To achieve the "multi-source optimization goal" that cold, power, gas, heat, and other energy sources can be utilized in a comprehensive and optimal manner, it is necessary to start from three aspects of the Energy Internet, that is, economy, energy, and environmental protection. Therefore, this project established a two-level index system from these three dimensions for the "comprehensive evaluation" of intelligent energy utilization in the park, as shown in Figure 4. 


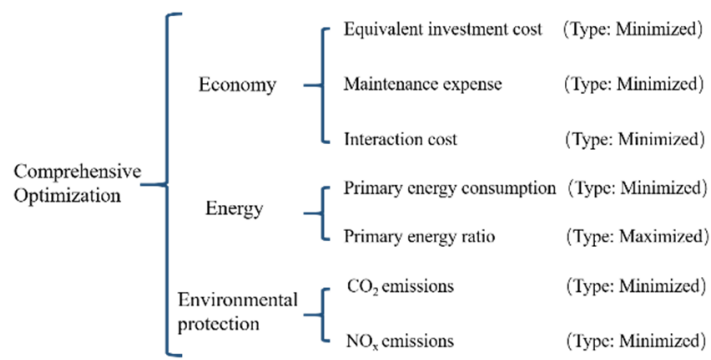

Fig. 4. Evaluation Index System

According to the AHP, the multi-attribute index system can be divided into two levels, in which "comprehensive optimization" includes four aspects in the first level, that is, economy, energy, environmental protection, and reliability. Furthermore, each aspect of the first level includes several second-level indicators with different attributes.

This paper took economy, energy, and environmental protection as the three first-level indicators. According to the three first-level indicators, several second-level indicators with different attributes were built, which included equivalent investment cost, maintenance expense, interaction cost, primary energy consumption, primary energy ratio, $\mathrm{CO}_{2}$ emissions, and NOx emissions. By means of the three first-level indicators and seven secondlevel indicators, the multi-attribute index system of intelligent energy utilization in the park was established.

To establish the evaluation model of the integrated energy utilization system in the park, weights should be assigned to the first-level and second-level indicators. According to the AHP, experts or decision-makers can judge the relative importance of each first-level and second-level index, so as to solve the subjective weight of the index by using the quantitative value of relative importance. To ensure the consistency of the decisionmaking logic of experts or decision-makers, logical consistency judgment is also required. The anti-entropy weight method is then used to obtain the objective weights of the indicators based on the normalized values of the second-level indicators. To avoid the indicator weights from being too objective or subjective, the linear weighting principle is used to combine the obtained subjective and objective weights, so as to calculate the combined weight of the second-level indicators.

The combined weight can be obtained by means of linear combination, which can be expressed as

$$
\left\{\begin{array}{l}
\omega_{j}=\lambda_{1} \omega_{j}^{\prime}+\lambda_{2} \omega_{j}^{\prime \prime} \\
\lambda_{1}+\lambda_{2}=1
\end{array}\right.
$$

where $\omega$ is the weight vector and $\lambda_{1}, \lambda_{2}$ are the linear combination coefficients.

Obtaining the linear combined weights is to determine the appropriate combination coefficients. On the one hand, it can ensure that the generalized weighted distance between all the solutions and the ideal solution is minimized, that is,

$$
\begin{aligned}
& \operatorname{Min} \sum_{i=1}^{m} \beta_{i}=\sum_{i=1}^{m} \sum_{j=1}^{n} \\
& \left(\lambda_{1} \omega_{j}^{\prime}\left(1-b_{i j}\right)+\lambda_{2} \omega_{j}^{\prime \prime}\left(1-b_{i j}\right)\right) \\
& \left(\lambda_{1}, \lambda_{2}\right)=\left(\frac{s_{1}}{\sum_{k=1}^{2} s_{k}}, \frac{s_{2}}{\sum_{k=1}^{2} s_{k}}\right) \\
& s_{1}=\exp \left\{-\left[1+\frac{\mu \sum_{i=1}^{m} \sum_{j=1}^{n} \omega_{j}^{\prime}\left(1-b_{i j}\right)}{1-\mu}\right]\right\}
\end{aligned}
$$

where $\beta$ is the generalized distance between solution $i$ and the ideal solution.

On the other hand, the uncertainty coefficients of the combination coefficients should be eliminated as much as possible. According to Jaynes's maximum entropy principle, the obtained combined weight coefficients of indicators determine the maximum value of the information entropy $H$, which can be expressed as

$$
\operatorname{Max} H=-\sum\left(\lambda_{1} \ln \left(\lambda_{1}\right)+\lambda_{2} \ln \left(\lambda_{2}\right)\right)
$$

By using a linearly weighted optimization method, the following single objective can be constructed.

$$
\operatorname{Min} \mu \sum_{i=1}^{m} \sum_{j=1}^{n}\left[\begin{array}{l}
\left(\lambda_{1} \omega_{j}^{\prime}+\lambda_{2} \omega_{j}^{\prime \prime}\right)\left(1-b_{i j}\right) \\
+(1-\mu) \sum_{k=1}^{2} \lambda_{k} \ln \left(1-\lambda_{k}\right)
\end{array}\right]
$$

where $\mu$ is the equilibrium coefficient between the two objectives, $0<\mu<1$.

The Lagrange function can be constructed to solve this single-objective optimization problem, and the linear combination coefficients $\lambda_{1}$ and $\lambda_{2}$ are calculated as follows.

$$
\begin{aligned}
& \left(\lambda_{1}, \lambda_{2}\right)=\left(\frac{s_{1}}{\sum_{k=1}^{2} s_{k}}, \frac{s_{2}}{\sum_{k=1}^{2} s_{k}}\right) \\
& s_{1}=\exp \left\{-\left[1+\frac{\mu \sum_{i=1}^{m} \sum_{j=1}^{n} \omega_{j}^{\prime}\left(1-b_{i j}\right)}{1-\mu}\right]\right\} \\
& s_{2}=\exp \left\{-\left[1+\frac{\mu \sum_{i=1}^{m} \sum_{j=1}^{n} \omega_{j}^{\prime \prime}\left(1-b_{i j}\right)}{1-\mu}\right]\right\}
\end{aligned}
$$

\section{Evaluation of Integrated Energy System Design Solution of Airports}

\subsection{System Design Solutions}

In this section, five design solutions are selected for comparison with one economic optimization solution, and the specific composition of the six solutions is shown in Table 2 . 
Table 2. Font styles for a reference to a journal article.

\begin{tabular}{|c|c|}
\hline Solution & Composition \\
\hline $\begin{array}{c}\text { 1.No energy } \\
\text { storage solution (I) }\end{array}$ & $\begin{array}{l}\text { Power grid + heat network+ } \\
\text { CCHP + GSHP + gas boiler }+ \\
\text { ASHP + direct-fired chiller }\end{array}$ \\
\hline $\begin{array}{l}\text { 2.No energy } \\
\text { storage solution } \\
\text { (II) }\end{array}$ & $\begin{array}{l}\text { Power grid + heat network+ } \\
\text { CCHP + GSHP + electric boiler } \\
+ \text { ASHP + direct-fired chiller }\end{array}$ \\
\hline $\begin{array}{l}\text { 3.Heat storage only } \\
\text { solution }\end{array}$ & $\begin{array}{c}\text { Power grid + heat network+ } \\
\text { CCHP + GSHP + electric boiler } \\
+ \text { heat storage device }+ \text { ASHP }+ \\
\text { direct-fired chiller }\end{array}$ \\
\hline $\begin{array}{l}\text { 4.Ice storage only } \\
\text { solution }\end{array}$ & $\begin{array}{c}\text { Power grid + heat network+ } \\
\text { CCHP + GSHP + electric boiler } \\
+ \text { ASHP + absorption chiller+ ice } \\
\text { storage unit }\end{array}$ \\
\hline $\begin{array}{l}\text { 5.Economic } \\
\text { optimization } \\
\text { solution }\end{array}$ & $\begin{array}{c}\text { Power grid }+ \text { heat network }+ \\
\text { CCHP + GSHP + gas boiler }+ \\
\text { ASHP + absorption chiller }+ \text { ice } \\
\text { storage unit }\end{array}$ \\
\hline $\begin{array}{l}\text { 6.Heat and ice } \\
\text { storage solution }\end{array}$ & $\begin{array}{c}\text { Power grid + heat network+ } \\
\text { CCHP + GSHP + electric boiler } \\
\text { heat storage device +ASHP } \\
\text { absorption chiller+ ice storage } \\
\text { unit }\end{array}$ \\
\hline
\end{tabular}

(1) No Energy Storage Solution (I) A

Electricity is mainly provided by CCHP and purchased from large power grids. Heat is mainly provided by GSHP and purchased from heat networks, and the remaining heat demand is provided by gas boilers. Cooling is mainly provided by GSHP, absorption chiller units, ASHP, and direct-fired chillers.

(2) No Energy Storage Solution (II) B

Electricity is mainly provided by CCHP and purchased from large power grids. Heat is mainly provided by GSHP and CCHP and purchased from heat networks, and the remaining heat demand is provided by electric boilers. Cooling is mainly provided by GSHP, absorption chiller units, ASHP, and direct-fired chillers.

(3) Heat Storage Only Solution C

Electricity is mainly provided by CCHP and purchased from large power grids. Heat is mainly provided by GSHP and CCHP and purchased from heat networks, and the remaining heat demand is provided by electric boilers. Peak clipping is carried out by heat storage devices. Cooling is mainly provided by GSHP, absorption chiller unit, ASHP, and direct-fired chillers.

(4) Ice Storage Only Solution D

Electricity is mainly provided by CCHP and purchased from power grids. Heat is mainly provided by GSHP and CCHP and purchased from heat networks, and the remaining heat demand is provided by electric boilers. Peak clipping is carried out by heat storage devices. Cooling is mainly provided by GSHP, absorption chiller units, ASHP, and ice storage units.

(5) Economic Optimization Solution E

Electricity is mainly provided by CCHP and purchased from power grids. Heat is mainly provided by GSHP, CCHP, and gas boilers, and purchased from heat networks. Cooling is mainly provided by GSHP, absorption chiller units, ASHP, and ice storage units.
(6) Heat and Ice Storage Solution F

Electricity is mainly provided by CCHP and purchased from power grids. Heat is mainly provided by GSHP and CCHP and purchased from heat networks, and the remaining heat demand is provided by electric boilers and heat storage devices. Peak clipping is carried out by heat storage devices. Cooling is mainly provided by GSHP, absorption chiller units, ASHP, and ice storage units.

\subsection{Quantification of Evaluation Indexes of Design Solutions}

To evaluate the six solutions for decision making, a quantitative analysis was conducted for the seven secondlevel indicators above.

(1) Obtaining subjective weights based on the AHP

A first-level indicator matrix of order 3 and a secondlevel indicator matrix of order 7 were constructed to judge the relative importance of all these indicators. Based on the judgment matrix of the first- and second-level indicators, the subjective weights of each first- and second-level indicator were obtained, which were shown in Table 3.

Table 3. Subjective Weights of First- and Second-Level Indicators

\begin{tabular}{|c|c|c|}
\hline & Indicators & Subjective weight \\
\hline \multirow{3}{*}{$\begin{array}{l}\text { First-level } \\
\text { indicators }\end{array}$} & Economy $\mathrm{W}_{1}$ & 0.413 \\
\hline & Energy $\mathrm{W}_{2}$ & 0.260 \\
\hline & Environment $\mathrm{W}_{3}$ & 0.327 \\
\hline \multirow{7}{*}{$\begin{array}{l}\text { Second- } \\
\text { level } \\
\text { indicators }\end{array}$} & $\begin{array}{c}\text { Equivalent } \\
\text { investment cost } \mathrm{W}_{11}\end{array}$ & 0.343 \\
\hline & $\begin{array}{l}\text { Maintenance } \\
\text { expense } W_{12}\end{array}$ & 0.308 \\
\hline & Interaction cost $\mathrm{W}_{13}$ & 0.349 \\
\hline & $\begin{array}{c}\text { Primary energy } \\
\text { consumption } \mathrm{W}_{21}\end{array}$ & 0.504 \\
\hline & $\begin{array}{l}\text { Primary energy ratio } \\
\qquad \mathrm{W}_{22}\end{array}$ & 0.496 \\
\hline & $\mathrm{CO}_{2}$ emissions $\mathrm{W}_{31}$ & 0.519 \\
\hline & $\mathrm{NO}_{\mathrm{x}}$ emissions $\mathrm{W}_{32}$ & 0.481 \\
\hline
\end{tabular}

\subsection{Comprehensive Evaluation of Design Solutions}

By substituting the normalized index values and the obtained subjective weights of the first-level indicators and the combined weights of the first- and second-level indicators into the evaluation model, it could be obtained that the evaluation value of the no energy storage solution (I) was 0.217 , the evaluation value of the no energy storage solution (II) was 0.083 , the evaluation value of the heat storage only solution was 0.109 , the evaluation value of the ice storage only solution was 0.682 , the evaluation 
value of the economic optimization solution was 0.963 , and the evaluation value of the heat and ice storage solution was 0.754 . According to the evaluation values of the solutions, the solutions could be ranked as economic optimization solution $>$ heat and ice storage solution $>$ ice storage only solution $>$ no energy storage solution (I) $>$ heat storage only solution $>$ no energy storage solution (II).

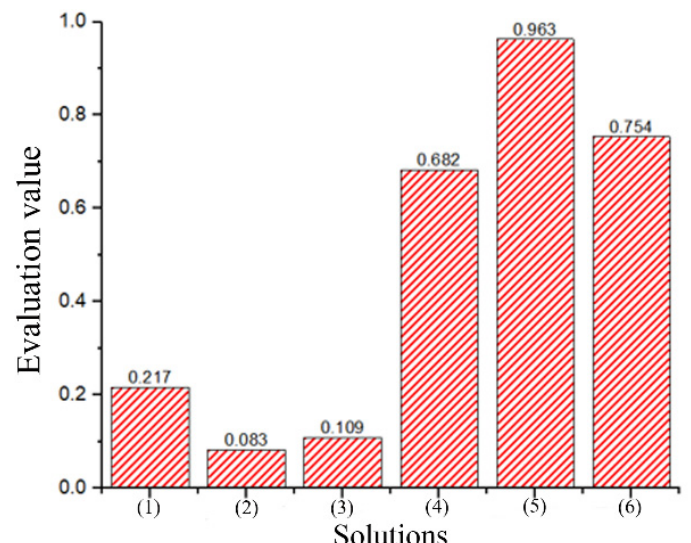

Fig. 5. Comprehensive Evaluation of System Solutions

Comparing the no storage solution (II) with the cold storage only solution and the economic optimization solution, we could see that the fuel cost decreased due to the ice storage devices shifting the power consumption of chillers during the electricity price peak. Besides, since the cold load peak almost covered the two electricity price peaks in summer, the fuel cost decreased more, resulting in increased revenue.

Comparing the ice storage only solution with the economic optimization solution and the heat and ice storage solution, we could see that all three solutions used an ice storage system that took advantage of low electricity prices at night to store ice and release it at peak electricity prices, which could greatly reduce gas consumption and thus pollutant emissions compared to direct-fired chillers. The economic optimization solution used gas boilers instead of electric boilers (mainly coalfired), making the solution more economical and reducing energy consumption and pollutant emissions.

\section{Conclusion}

For the integrated energy system in the airport project, this paper established an evaluation model of different integrated energy design solutions and completed the comparison of six typical integrated energy solutions in airports by using a comprehensive weighting method based on the analytic hierarchy process (AHP) and antientropy weight method.

The economic optimization solution can significantly reduce the fuel cost through the combination of ice storage, $\mathrm{CCHP}$, and gas boilers, while the equivalent investment cost of the heat and ice storage solution reduces the economic advantage of this solution.

From the analysis of energy indicators composed of primary energy ratio and primary energy consumption, the configuration of electric boilers in the integrated energy system will significantly reduce the system energy indicators.
From the analysis of environmental indicators consisting of pollutant emissions, energy storage devices including heat and ice storage devices can significantly reduce the pollutant emissions of the integrated energy system.

This paper evaluated and analyzed the design solutions of the integrated energy system in airports from multiple perspectives, which provides design ideas for the construction of the airport energy station with optimal comprehensive indexes.

\section{Acknowledgement}

This work was supported by Natural Science Basic Research Program of Shaanxi (Grant No.2020JQ-1001).

\section{References}

1. LI Jinghua, HUANG Yujin, ZHANG Peng, Review of Multi-Energy Flow Calculation Model and Method in Integrated Energy System[J]. Electric Power Construction, 2018, 39(03):1-11.

2. GEIDL M , KOEPPEL G, FAVREPERROD P, et al. Energy hubs for the future[J]. Power \& Energy Magazine IEEE, 2007, 5(1):24-30.

3. SHAO Chengcheng, WANG Xifan, et al. Probe into Analysis and Planning of Multi-energy Systems[J]. Proceedings of the CSEE, 2016, 14: 3817-3829.

4. HONG Xiao. Multi-energy coordination evaluation model of regional energy internet [D]. Beijing: North China Electric Power University, 2018.

5. WU Qiang, CHENG Lin, HUANG He, et al. Energy Internet comprehensive energy efficiency evalua-tion method based on analytic hierarchy process [J]. Electrical Application, 2017,36(17):62-68.

6. DONG Fugui, ZHANG Ye , SHANG Meimei . Multi -criteria comprehensive evaluation of distributed energy system[J]. Proceedings of the CSEE, 2016,36(12): 3214-3222.

7. ZHU Xiaochen, NIU Dapeng, WANG Xu, et al. Comprehensive energy saving evaluation of circulating cooling water system based on combination weighting method[J]. Applied Thermal Engineering. 2019,157 .

8. CHEN Baisen, LIAO Qingfen, LIU Dianchen, WANG Wenyi, WANG Zhiyi, CHEN Siyuan. Comprehensive evaluation index and method of re-gional integrated energy system [J]. Automation of Power System, 2018,42(04):174-182.

9. ZHANG Shixiang, LU Shuaikang. Evaluation method of integrated energy system for microgrid in the park [J]. Grid Technology, 2018,42(08):24312439.

10. ZHANG Tao, ZHU Tong, GAO Naiping, et al. Optimization design of distributed cold, hot and elec-tric energy system and multi-index comprehensive evaluation method $[\mathrm{J}]$. Chinese Journal of Electri-cal Engineering, 2015,35(14):3706-3713. 
11. JIANG Ling, YUAN Yue, WANG Zheng, et al. Evaluation index and evaluation method of energy Internet in smart grid innovation demonstration zone [J]. Journal of Power System and Automation, 2016,28(1):39-45

12. YANG Yongbiao, ZHENG Hongjuan, HUO Xi-Xu, et al. Research on multi-source optimization and comprehensive assessment technology for small energy Internet $[\mathrm{J}]$. Electric Appliances and Energy Efficiency Management Technology, 2017(8):53-60.

13. WANG Yi, CHENG Jiangnan, ZHANG Ning, et al. Automatic and linearized modeling of energy hub and its flexibility analysis [J]. Applied Energy. 2018,211:705-714.

14. LIN Wei, JIN Xiaolong, MU Yunfei,et al. Mul-tiobjective optimal hybrid power flow algorithm for regional integrated energy system $[\mathrm{J}]$. Chinese journal of electrical engineer-ing,2017,37(20):5829-5839.

15. PENG Huaiwu, LI Angui, WANG Xin, et al. Distributed energy system evaluation matrix model and index quantification analysis based on IAHPvariation coefficient method [J]. Journal of Xi'an University of Architecture \& Technology (Natural Science Edition), 2020,52(04):572-578. 